tionales Recht Bd. 15 S. 822; dort wird seinerseits auf ILM 9 (1970), 99-126 verwiesen (das Jahrbuch hat jetzt bekanntlich einen anglizierten Namen).

Alles in allem ist die "International Law"-Sammlung wegen der Edition nahezu aller wichtigen, zudem authentischen Originaltexte eine Bereicherung. Studenten, Wissenschaftler und Praktiker erhalten die Möglichkeit des vereinfachten Zugriffs auf Quellen in zitierfähiger Form. Auch werden insbesondere am Seerecht und am Umweltschutzrecht Interessierte aktuelles Material in dem Buch finden, das in anderen Sammlungen i. d. R. so nicht enthalten ist. Angesichts der mit dem Pfund- und Dollarverfall preisgünstigen britisch-amerikanischen Alternativen macht es der Verlag indes nur bibliophilen Völkerrechtlern mit Paperback-Phobie leicht, dieses wichtige Werk für die eigene Bibliothek zu erwerben.

Wolfgang Graf Vitzthum

\title{
Oleg Kolbassow
}

\section{Umweltschutz und Völkerrecht}

Verlag Progress, Moskau, und Staatsverlag der Deutschen Demokratischen Republik, Berlin, 1985, $240 \mathrm{~S}$.

Der Autor ist Sektorenleiter für Rechtsprobleme des Umweltschutzes am Institut für Staat und Recht bei der Akademie der Wissenschaften der UdSSR und durch zahlreicher Schriften ausgewiesen, die sich vor allem dem Naturschutzrecht und dem Recht des Gewässerschutzes widmen. Die vorliegende Schrift war 1982 in russischer Sprache erschienen. Sie ist eine Selbstdarstellung der sowjetischen Umweltrechtspolitik und enthält demzufolge viele nützliche Informationen über das dortige Umweltrecht, trotz des Titels also nicht nur eine Darstellung des Umweltvölkerrechts, sondern auch des völkerrechtlich veranlaßten oder jedenfalls mit Völkerrecht in Zusammenhang zu bringenden nationalen Rechts. Darüberhinaus schildert sie die einschlägige Politik des östlichen Blockes auf internationaler Ebene, läßt auch Positionen zur Völkerrechtsentwicklung erkennen, die über das Umweltvölkerrecht hinaus von Interesse sind.

Zum Stand des Umweltschutzes, zur politischen Wechselbeziehung zwischen Umweltbeeinträchtigungen und rechtlichen Reaktionen hierauf, zu den Ursachen und Bedingungen von Umweltverschmutzung bietet Kolbassow eine eher krude Schuldzuweisung an "Kapitalismus" und "Imperialismus", spricht nicht von den verheerenden Gewässerund Atmosphärenverschmutzungen in Osteuropa, wohl aber davon, daß "Papageien" in "der BRD" angeblich "DM 15 000,- " kosten. Der Rhein sei eine Kloake, mit der Elbe wird er nicht verglichen. Westeuropäische Staaten erscheinen als Hauptabnehmer ostafrikanischen Elfenbeins (ohne daß wir von den arabischen Märkten lesen). Das Scheitern effektiven Wal-Schutzes wird konstatiert, der sowjetische Beitrag gerade dazu unterschlagen. Und Lenin, der immer wieder für Uberraschungen gut ist, habe eine "hervor- 
ragende Rolle bei der Erarbeitung der Theorie . . . des Umweltschutzes" gespielt (S. 26), auch wenn Umweltschutz einen für die Menschheit der Nachkriegszeit "neuen Tätigkeitsbereich" darstellt (S. 51).

Auch die Rolle der Entwicklungsländer im Weltsystem ist klar: Der Kapitalismus nutzt sie aus und schädigt damit ihre Umwelt; die Sowjetunion und ihr nahestehende Staaten sind bemüht, diesen Schaden gering zu halten, in dem sie kräftig wirtschaftliche und technische Hilfe leisten. Das unermüdliche Bemühen der Sowjetunion, das Umweltvölkerrecht voranzutreiben, wird immer wieder behindert durch Kapitalismus, Imperialismus, Zionismus und Rassismus ... .

Es sei nicht verschwiegen, daß Kolbassow, der ein äußerst sachkundiger Autor ist, das Maß seiner diesbezüglichen Bekundungen in einem noch erträglichen Rahmen hält. Wenn er ins Detail geht, wird der Text lesbar, genau und informativ. Bei der Schilderung regionaler Umweltschutzkooperation etwa werden die Aktivitäten von Europarat, EWG, OECD in ihren Grundzügen beschrieben und gewürdigt. Im Zentrum des Buches insgesamt steht der Bericht: Die Stockholmer Konferenz von 1972, UNEP, staatliche und nichtstaatliche internationale Organisationen und die dort jeweils erarbeiteten Vorgaben für den völkerrechtlichen Umweltschutz werden aufgeführt, soweit sich diese Vorgaben in Rechtsnormen oder wenigstens in Resolutionen ausdrücken. Innerstaatliche Umsetzung oder anderweitige Befolgung im "sozialistischen Lager" werden erwähnt. Diese Teile des Buches machen gut die Hälfte seines Umfanges aus, ihnen folgt eine systematische Bestandsaufnahme zum völkerrechtlichen Schutz einzelner "Objekte in der Natur". Der Gesamttenor der kritischen Betrachtung lautet dabei - grob gesagt: Es wird viel getan, aber es bedarf weiterer Fortschreibung und Zusammenarbeit - ein in dieser Abstraktion unangreifbarer Tenor also, der aber wenig darüber auszusagen vermag, warum und in welchen Bereichen Recht bisher nicht in der Lage war, Umweltbeeinträchtigungen wirksam zurückzubinden. Typisch für die methodische Perspektive ist, daß bei der Behandlung des marinen Umweltschutzes das Seerechts-Ubereinkommen von 1982 im Mittelpunkt steht, obwohl es in weiten Teilen vage bleibt und auf konkretisierende Verträge verweist, die längst in Kraft sind. Letztere, die ungleich bedeutsamer sind als das Ubereinkommen und deren Durchsetzung die eigentliche Weiche stellt für die Verminderung der Meeresverschmutzung, werden zwar erwähnt, aber nicht kritisch analysiert. So nimmt sich der Autor die Möglichkeit, etwa zur kontinuierlichen Olverschmutzung oder zur Schadstoffbelastung der Meere durch den Eintrag der Flüsse fundiert Stellung zu nehmen.

In einem Abschlußkapitel ("Fragen der Theorie und des internationalen Umweltrechts") geht Kolbassow u. a. auf die Herausforderungen ein, die das Umweltvölkerrecht an die völkerrechtliche Rechtsquellenlehre stellt: Inspiriert von dem Franzosen Kiss diskutiert er die Bedeutung nicht-verbindlicher Normen, muß freilich das Rätsel "soft law" so ungelöst lassen wie andere vor ihm.

Insgesamt ist das Buch eine beachtliche Neuerscheinung, die - parteiisch wie stets, selektiv und positivistisch wie meist - die sowjetische Einschätzung der Völkerrechtsentwicklung im Bereich des Umweltrechts erkennen läßt und die wegen ihrer Faktenfülle auch 
die Möglichkeit bietet, Einzelfragen nachzuschlagen. Daß der Staatsverlag der DDR die wichtigsten Werke führender sowjetischer Rechtswissenschaftler in deutscher Sprache zugänglich macht, ist ein erfreulicher Umstand.

Philip Kunig 